\title{
Utilização de ondas acústicas para caracterização de telhas cerâmicas: uma proposta didática de ensaio não destrutivo
}

Using acoustics waves for characterization of ceramic roof tiles: a didactic proposal of non-destructive test

\author{
Álvaro Barbosa de Carvalho Júnior $\sqrt{0}$, Maria Helena Teles Lopes ${ }^{* 10}$, Ana Caroline Nery Munoz \\ Carvalho $^{1}$, Antônio Wilson Vieira ${ }^{1}$, Denys Cunha Fonseca Garcia ${ }^{2}$ \\ ${ }^{1}$ Universidade Estadual de Montes Claros, Programa de Pós-Graduação em Modelagem Computacional e Sistemas, Montes \\ Claros, MG, Brasil. \\ ${ }^{2}$ Secretaria Estadual de Educação de Minas Gerais, Montes Claros, MG, Brasil.
}

Recebido em 13 de agosto de 2020. Revisado em 05 de setembro de 2020. Aceito em 15 setembro de 2020.

\begin{abstract}
Nesse estudo buscou-se desenvolver uma metodologia simples, capaz de caracterizar diferentes propriedades de telhas cerâmicas por meio da propagação de ondas acústicas. Para isso, foi utilizada a energia potencial gravitacional provocada pelo impacto de uma esfera de aço em queda livre sobre a superfície de telhas cerâmicas, sendo o sinal acústico capturado com o auxílio de um computador e um software livre. Os resultados obtidos mostraram a viabilidade do método como proposta didática a ser implementada nas aulas de laboratório de materiais de construção, ministradas regularmente nos cursos de Engenharia Civil.
\end{abstract}

Palavras-chave: onda acústica, telha, ensaio não destrutivo, propriedades.

\begin{abstract}
The aim of this study was to develop a simple methodology, capable of characterizing different properties of ceramic roof tiles through the acoustics waves propagation. For this, was used the gravitational potential energy caused by the impact of a steel ball in free fall on the roof tiles surface. After this, the acoustic signal was captured using computer and free software. The results obtained showed the viability of the method as a didactic proposal to be implemented in the classes building materials laboratory carried out in civil engineering courses.
\end{abstract}

Keywords: acoustic wave, roof tile, non-destructive test, properties.

\section{Introdução}

As disciplinas que envolvem conteúdos de física são de relevante importância nos cursos de Engenharia Civil, tendo em vista as análises dos esforços que atuam em uma determinada estrutura ou material. Durante o curso de graduação, os futuros engenheiros encontram diversas situações onde o conhecimento da física é utilizado. Por exemplo, os conteúdos sobre corrente elétrica, decomposição vetorial e propagação de ondas acústicas, contribuem de forma positiva para a compreensão e resolução de problemas relacionados às disciplinas de Eletrotécnica Geral, Resistência dos Materiais e Materiais de Construção, entre outras.

A disciplina de Materiais de Construção proporciona aos acadêmicos o conhecimento dos principais materiais utilizados nas edificações. Além disso, a disciplina oferece o contato direto com os materiais de construção e com os ensaios mecânicos que são utilizados para a caracterização de suas propriedades, tendo em vista que as propriedades físicas e mecânicas são requisitos importantes para a escolha de um material.

*Endereço de correspondência: mariahelenat123@gmail.com
No que se refere à caracterização dos materiais cerâmicos, os ensaios de compressão axial, resistência à flexão simples e de absorção de água, se destacam como os principais ensaios nas aulas de Materiais de Construção, sobretudo, para a investigação de blocos, tijolos e telhas cerâmicas.

Para a realização do ensaio de flexão simples em telhas é necessário uma instrumentação específica, como por exemplo, o uso de um equipamento capaz de aplicar uma carga contínua a uma razão de $50 \mathrm{~N} / \mathrm{s}$ ( $5 \mathrm{kgf} / \mathrm{s})$, sendo o valor da carga de ruptura aferido por meio de um dispositivo analógico ou digital, com sensibilidade de $10 \mathrm{~N}$ (1 kgf). Além disso, também é necessário o uso de barras de aço de seção circular ou semicircular e dispositivos de articulação específicos para cada tipo de telha ensaiada [1].

Para realizar o ensaio de absorção de água, a instrumentação é simples e consiste apenas em uma balança com sensibilidade de $10 \mathrm{~g}$, uma estufa com temperatura ajustável em torno de $105^{\circ} \mathrm{C}$ e um recipiente com capacidade de acomodar as telhas submersas. Como resultado, o limite máximo de absorção de água esperado não deve ser maior do que $20 \%$ em relação ao peso da telha [1]. 
Geralmente, a quantidade de corpos de prova utilizados nos ensaios segue a recomendação das normas técnicas, que sugerem o uso de no mínimo cinco telhas para cada ensaio. Depois de ensaiadas, os fragmentos das telhas são descartados, contribuindo para o aumento de resíduos sólidos gerados durante as aulas nos laboratórios de ensaios de materiais.

Por outro lado, os ensaios não destrutivos consistem em técnicas capazes de inspecionar um material sem a necessidade de destruí-lo ou danificá-lo. Dessa forma, os ensaios não destrutivos podem ser utilizados para verificar de forma rápida se o material investigado está adequado para atender ao desempenho desejado. A grande maioria dos ensaios não destrutivos utilizam métodos com princípios da física. Por exemplo, os conceitos de onda eletromagnética, campo elétrico e propagação de ondas acústicas, são, respectivamente, os princípios fundamentais dos ensaios por raios $\mathrm{X}$, partículas magnéticas e do ensaio por ultrassom. É importante ressaltar que esses ensaios são utilizados com êxito na caracterização de diferentes tipos de materiais [2].

Sabe-se que as velocidades das ondas acústicas podem ser relacionadas com várias propriedades físicas e mecânicas dos materiais, tais como, impedância, dureza, temperatura de Debye, e os módulos de compressibilidade, elasticidade e cisalhamento [3-5]. De maneira semelhante, as velocidades de ondas ultrassônicas podem ser usadas com sucesso para a determinação da resistência de tração na flexão em diferentes tipos de telhas cerâmicas [6].

Para a determinação das propriedades físicas e mecânicas de um material é necessário a realização de mais de um ensaio destrutivo. Isso mostra a potencialidade dos ensaios que utilizam ondas acústicas, a exemplo do ensaio por ultrassom, que pode estimar várias propriedades elásticas por meio da propagação de ondas longitudinais e transversais. Portanto, os ensaios que utilizam ondas acústicas podem reduzir os custos com a preparação de amostras e diminuir o tempo de aquisição dos resultados, uma vez que não seria necessário a realização de ensaios destrutivos convencionais.

Considerando os aspectos abordados acima, este trabalho buscou desenvolver uma metodologia simples capaz de gerar e capturar sinais acústicos em telhas cerâmicas, com o intuito de caracterização de suas propriedades. Para isso, foram avaliados os sinais acústicos produzidos com o impacto de uma esfera de aço em queda livre sobre as superfícies de amostras de telhas cerâmicas, sendo os sinais acústicos relacionados com o percentual de absorção e com a resistência à flexão simples das telhas. Espera-se que os conceitos físicos aplicados na obtenção dos resultados possam contribuir de forma positiva com as aulas de laboratório de Materiais de Construção realizadas nos cursos de Engenharia Civil.

\section{Materiais e Métodos}

\subsection{Características das amostras de telhas cerâmicas}

Para a realização deste estudo foram adquiridas comercialmente amostras de telhas cerâmicas nas cores branca e vermelha. As telhas brancas são do tipo americana (capa e canal), resinadas, com dimensões de largura, comprimento e espessura, aproximadas de $28 \mathrm{~cm} \mathrm{x} 44 \mathrm{~cm} \mathrm{x} 1$ $\mathrm{cm}$. A massa média obtida com a pesagem de três telhas foi de $3,150 \mathrm{~kg} \pm 0,05 \mathrm{~kg}$. Essas telhas são procedentes do estado de Santa Catarina (SC) e, segundo a certificação do fabricante, elas possuem resistência à flexão simples de 250 kgf e absorção de água de $4 \%$.

As telhas vermelhas, não resinadas, também são do tipo americana (capa e canal) e possuem as mesmas dimensões das telhas brancas. Entretanto, essas telhas são procedentes do estado de Minas Gerais (MG). A massa média obtida com três telhas foi de aproximadamente $3,220 \mathrm{~kg} \pm 0,03 \mathrm{~kg}$. De acordo com a certificação do fabricante, as amostras de telhas vermelhas possuem resistência à flexão simples de 180 kgf e absorção de água de $13 \%$. A Figura 1 apresenta as amostras das telhas cerâmicas selecionadas para este estudo.

Por meio de inspeção visual foi constatado que as amostras de telhas não apresentavam diferenças significativas no seu formato ou no número de defeitos sistemáticos de fabricação, como por exemplo, rebarbas existentes nas bordas. Para verificar as diferenças existentes na superfície externa das telhas, ou seja, a morfologia da superfície, foram feitos registros de imagens com o auxílio de um microscópio óptico digital, da marca Proscope USB, com aumento de 10 vezes.

\subsection{Geração e captura dos sinais acústicos na superfície das telhas}

Para analisar a propagação das ondas acústicas nas telhas foi realizado um experimento simples que utiliza uma esfera de aço e um software livre que simula um osciloscópio. As ondas acústicas foram geradas por meio do impacto provocado pela esfera de aço em queda livre sobre a superfície das telhas. A esfera utilizada possui diâmetro de 2,4 cm e massa igual a 54,9 g. A altura de queda livre foi de aproximadamente $2 \mathrm{~cm}$. As ondas acústicas foram geradas com uma pequena energia potencial gravitacional em torno de $0,0108 \mathrm{~J}$, obtida por meio da

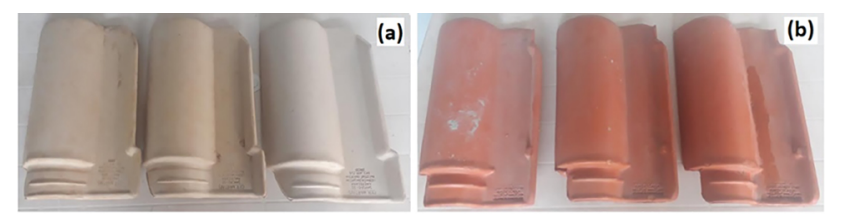

Figura 1: Amostras de telhas cerâmicas: (a) telha branca e (b) telha vermelha. 
equação (1).

$$
E_{p}=m g \cdot h
$$

onde: $m=$ massa $(\mathrm{kg}) ; g=$ aceleração da gravidade $(9,8$ $\left.\mathrm{m} / \mathrm{s}^{2}\right) ; h=$ altura de queda livre da esfera de aço $(\mathrm{m})$.

Com o intuito de que a esfera fosse abandonada em queda livre sempre da mesma posição foi utilizado um tubo de PVC com $2 \mathrm{~cm}$ de altura. O diâmetro do tubo foi de $2,54 \mathrm{~cm}$, que é um pouco maior do que o diâmetro da esfera. A medida da altura de queda livre foi escolhida de modo a não provocar o quique da esfera de aço, sendo cada sinal acústico obtido com um único impacto. A Figura 2 mostra um esquema representativo da geração das ondas acústicas na superfície externa superior das telhas cerâmicas.

Os sinais das ondas acústicas gerados com o impacto da esfera foram capturados com o auxílio do software Soundcard Oscilloscope, que consiste em um osciloscópio digital com interface visual muito semelhante a um osciloscópio convencional. A amplitude dos sinais foi avaliada em função do tempo de percurso da onda acústica, na faixa compreendida entre 0 e 60 milissegundos (ms). Como receptor dos sinais acústicos foi utilizado um fone de ouvido estéreo, Plug P2, com microfone embutido. O fone foi fixado sobre a cumeeira das telhas a uma distância de $30 \mathrm{~cm}$ em relação ao local do impacto da esfera. A Figura 3 ilustra a montagem do experimento, onde os círculos vermelhos indicam o posicionamento do fone receptor fixado com fita adesiva em uma das extremidades da telha. A Figura 4 exemplifica um sinal de onda acústica capturado com o software Soundcard Oscilloscope e apresentado na tela do computador.

É importante ressaltar que o tipo de fone de ouvido, utilizado como receptor dos sinais, não apresenta sensibilidade suficiente para captar pequenos ruídos ou vibrações externas, que poderiam ser transmitidas para o osciloscópio digital, interferindo nas medidas. Esse fato pode ser evidenciado pela linha vermelha apresentada logo abaixo do sinal acústico na Figura 4. A linha vermelha representa o sinal na tela do osciloscópio antes das medidas, enquanto que a linha verde representa o sinal acústico depois do impacto. Logo, é possível observar a ausência de ruídos ou vibrações externas antes da realização das medidas.

O comportamento do sinal acústico foi analisado em 03 telhas brancas e em 03 telhas vermelhas. Para cada amos-
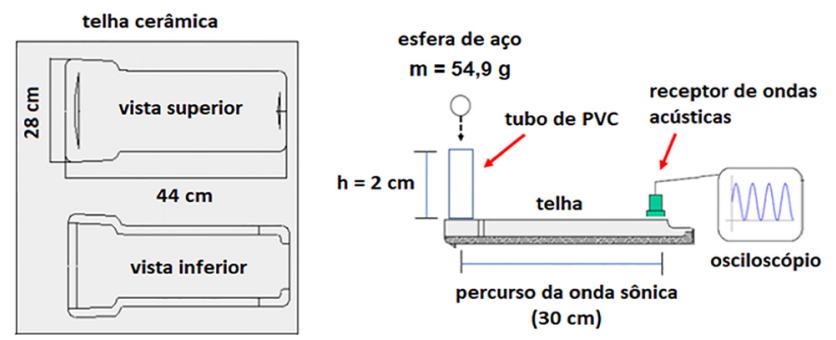

Figura 2: Esquema da geração das ondas acústicas nas telhas cerâmicas.

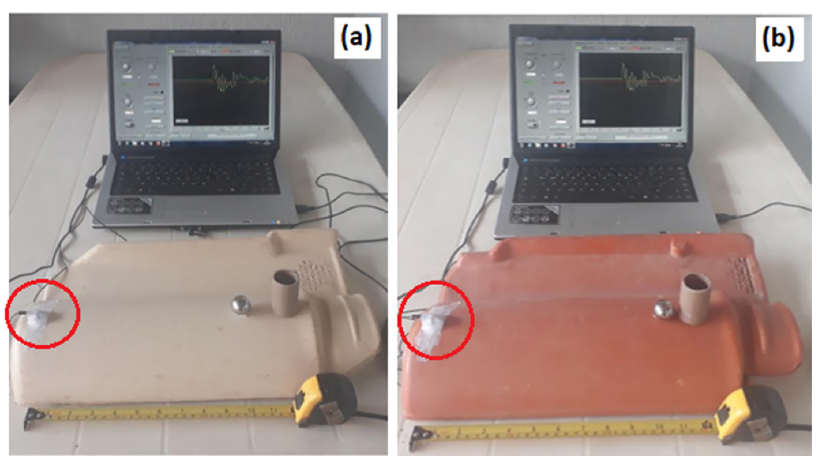

Figura 3: Montagem do experimento para geração e captura do sinal acústico nas telhas: (a) amostra de telha branca e (b) amostra de telha vermelha.

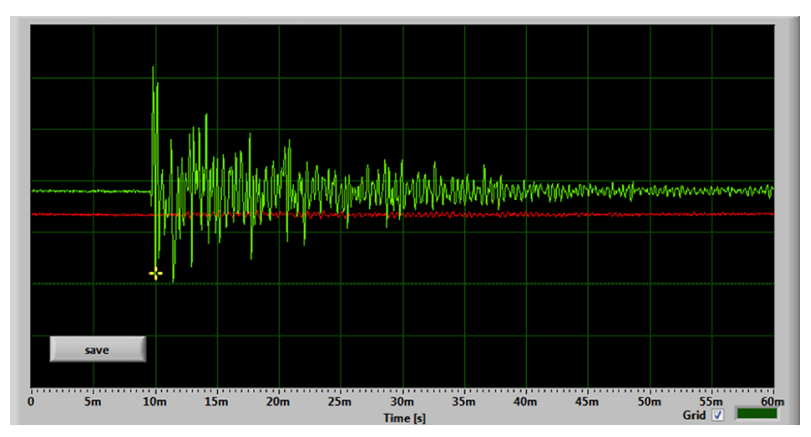

Figura 4: Exemplo do sinal acústico capturado na superfície das telhas cerâmicas.

tra de telha foram realizadas 20 medidas, sendo os dados exportados para programa Origin7.0 $0^{R}$, que ofereceu os recursos para as análises matemáticas. Os experimentos dessa pesquisa foram realizados nas dependências do Programa de Pós-Graduação em Modelagem e Sistemas da Universidade Estadual de Montes Claros - MG (PPGMCS/UNIMONTES).

\subsection{Análise do comportamento dos sinais acústicos}

Depois de analisar o comportamento dos sinais acústicos não foram observadas mudanças significativas na forma dos sinais, além de uma pequena variação nos valores de amplitudes. De maneira geral, as medidas realizadas foram bastante reprodutíveis, sendo possível obter um sinal médio característico para ambas as telhas.

Para analisar o decaimento dos sinais em função do tempo de percurso da onda acústica foram escolhidos 12 pontos distintos, situados nos valores máximos das amplitudes decrescentes, conforme ilustra a Figura 5. Em seguida, para verificar se o decaimento do sinal acústico ocorre de forma exponencial foi utilizada uma função para o ajuste desses pontos. Essa análise foi realizada com o auxílio do programa Origin $7.0^{R}$, utilizando a ferramenta Analysis/Fit_Exponential Decay.

Buscando diferenciar os sinais acústicos entre as telhas branca e vermelha, tentou-se calcular o coeficiente de 


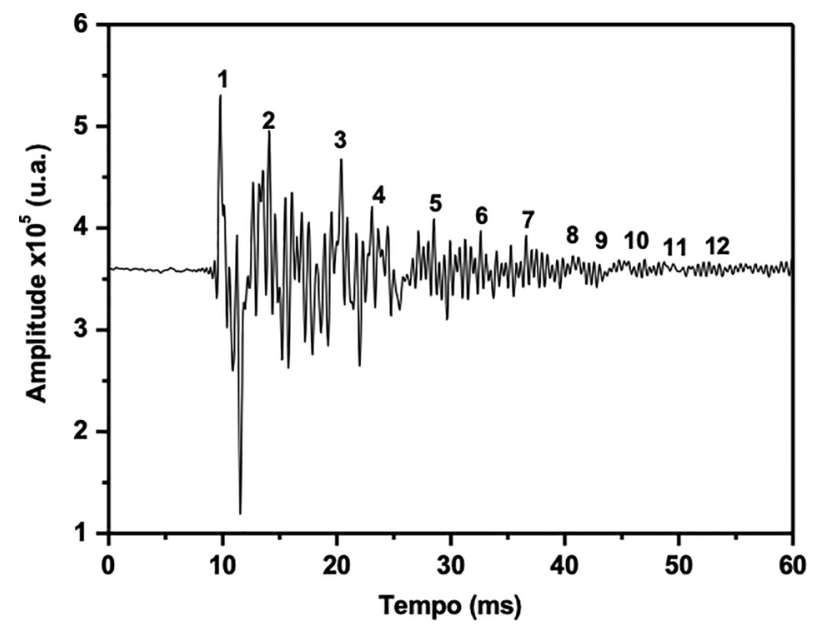

Figura 5: Exemplo do sinal acústico obtido no programa Origin $7.0^{R}$.

atenuação da onda acústica por meio da equação (2), a qual foi proposta por outros autores [7, p. 109]. Inicialmente, para o cálculo do coeficiente de atenuação foram utilizados os valores máximos entre duas amplitudes adjacentes. Entretanto, esse procedimento não se mostrou adequado para calcular o coeficiente de atenuação das telhas, pois, embora sejam decrescentes, algumas amplitudes adjacentes possuem valores muito próximos.

$$
\alpha=20 \cdot \frac{\log \left(A / A_{0}\right)}{X}
$$

onde: $\alpha=$ coeficiente de atenuação da onda acústica (dB/cm); $A=$ amplitude inicial escolhida; $A=$ amplitude final adjacente; $X=$ distância percorrida pela onda acústica $(\mathrm{cm})$.

O ponto 1 na Figura 5 é considerado como amplitude no momento do impacto, enquanto os pontos de 2 a 12 foram admitidos como sendo as amplitudes de reflexão da onda acústica. $\mathrm{O}$ valor admitido como distância percorrida pela onda acústica para que haja amplitudes de reflexão foi de $60 \mathrm{~cm}$, que corresponde a duas vezes a distância entre o local de impacto da esfera e o fone receptor. Os pontos representando as amplitudes máximas decrescentes são compostos por vários picos de amplitudes sobrepostos. Portanto, para o cálculo do coeficiente de atenuação foi adotado o valor médio dos picos sobrepostos que compõe os pontos de 2 a 5 , tendo em vista que os pontos de 6 a 12 já se encontram na região amortecida da onda acústica.

O ponto de maior amplitude do sinal, que corresponde ao momento do impacto da esfera de aço sobre a superfície da telha, também foi investigado com o propósito de diferenciar os sinais acústicos. Para essa análise foram realizadas ampliações nas regiões desses pontos observados nas telhas. As ampliações foram feitas com o auxílio programa Origin7.0 ${ }^{R}$. Depois disso, foram realizadas ampliações nas regiões dos pontos de 1 a 4 , visando investigar os valores de intervalos de tempo.
Para decompor a função temporal do sinal acústico no domínio da frequência foi utilizado o método da Transformada Rápida de Fourier (Fast Fourier Transform $F F T$ ), que é bastante utilizado no estudo de processamento de sinais e várias outras aplicações da física e engenharia $[8,9]$. Esse procedimento teve como objetivo extrair informações sobre as frequências excitadas nas telhas durante a propagação da onda acústica. A análise foi realizada com o programa Origin $7.0^{R}$, utilizando a ferramenta Analysis/FFT, que corresponde à função da Transformada Rápida de Fourier.

\section{Resultados e Discussão}

\subsection{Análise dos sinais acústicos das telhas}

Os sinais acústicos médios obtidos para as telhas branca e vermelha estão apresentados nas Figuras 6 e 7, respectivamente. Os pontos de 2 a 12 indicados nas figuras representam os valores máximo das amplitudes de reflexão decrescente. Esses pontos consistem em picos de amplitudes sobrepostos que são mais bem observados

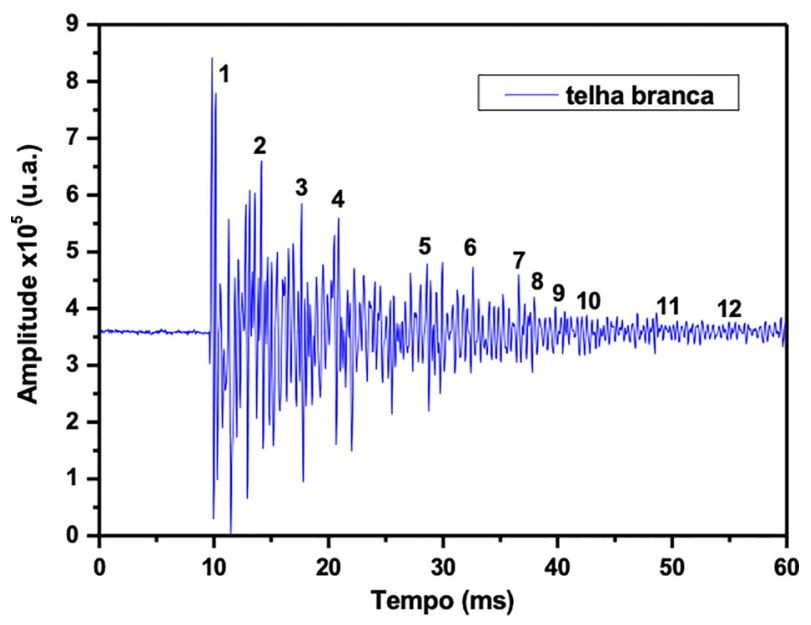

Figura 6: Sinal acústico médio para a telha branca.

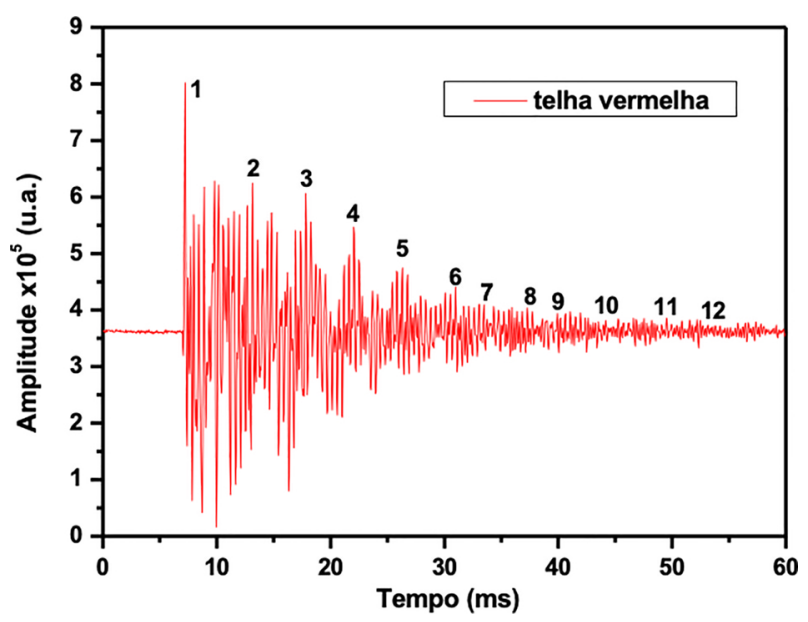

Figura 7: Sinal acústico médio para a telha vermelha. 
após uma ampliação da região. Durante o experimento, uma pequena variação foi constatada nos valores das amplitudes de reflexão entre uma medida e outra. Essa variação é decorrente do procedimento adotado no experimento para a liberação da esfera em queda livre, onde pode ocorrer mudanças milimétricas na altura adotada de $2 \mathrm{~cm}$.

Observando os sinais acústicos das telhas branca e vermelha fica difícil constatar de forma clara as diferenças existentes entre eles. Portanto, como primeira análise foi investigado o decaimento dos sinais em função do tempo de percurso da onda acústica. As Figura 8 e 9 apresentam o decaimento em função do tempo obtidos por meio do ajuste dos 12 pontos de amplitudes decrescentes. Os pontos apresentados nessas figuras representam os valores médios da amplitude e seus respectivos desvios padrão. Como resultado, nota-se pelas barras de erro nos sinais médios que as medidas realizadas nas telhas branca e vermelha foram bem reprodutíveis, decaindo exponencialmente em função do tempo, conforme sugerem os valores encontrados de $\mathrm{R}^{2}=0,97$.

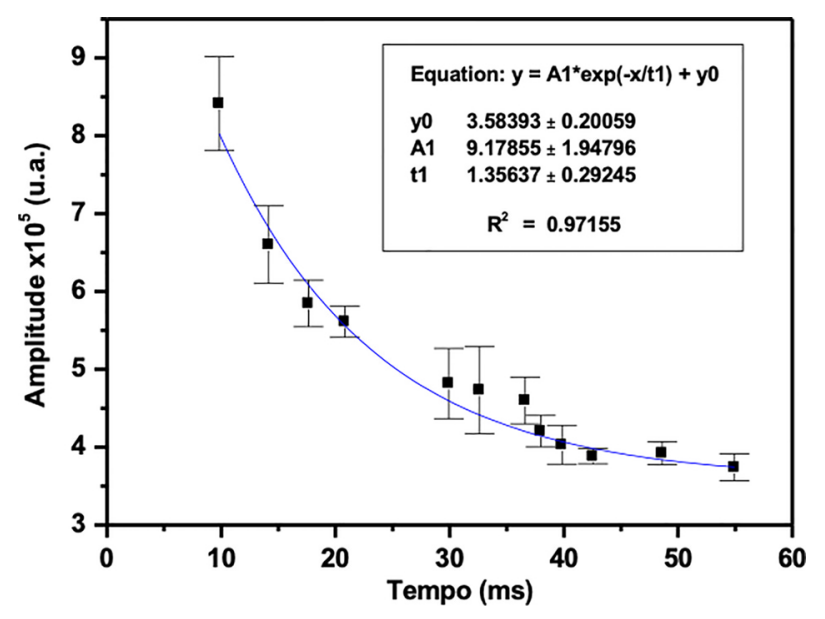

Figura 8: Decaimento do sinal acústico para a telha branca.

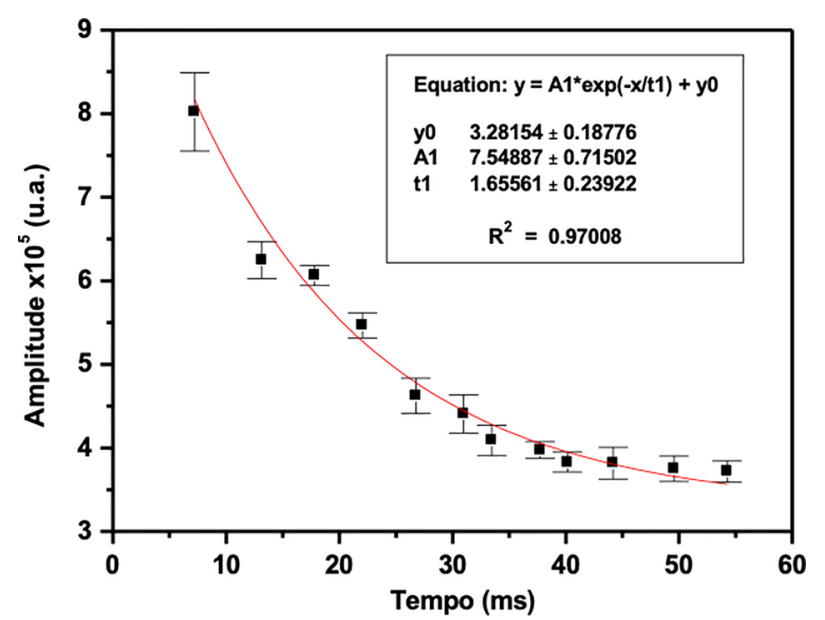

Figura 9: Decaimento do sinal acústico para a telha vermelha.
As ondas acústicas ao percorrerem um material sólido sofrem em sua trajetória os efeitos da dispersão e da absorção, resultando na redução de sua energia. A dispersão é um fenômeno que ocorre nos materiais não homogêneos, que apresentam interfaces naturais na sua própria estrutura, muitas vezes decorrentes do processo de fabricação [7, p. 110 e 167]. Já o fenômeno da absorção ocorre sempre que a onda acústica percorre um material, sendo sua energia cedida para que cada partícula do meio execute um movimento oscilatório, transmitindo a vibração para outras partículas do próprio meio [4].

Os efeitos combinados da dispersão e absorção resultam no fenômeno da atenuação da onda acústica, que é responsável pelo decaimento exponencial da onda propagada no decorrer do tempo. Assim, os resultados apresentados nas Figuras 8 e 9 estão de acordo com o esperado, embora não apresentem de forma clara diferenças que possam ser relacionadas com as propriedades mecânicas e físicas das telhas investigadas.

\subsection{Estimativa do coeficiente de atenuação $(\alpha)$}

Para tentar estimar o coeficiente de atenuação da onda acústica por meio da equação (2), foram utilizados os valores médios das amplitudes sobrepostas que constituem os pontos de 2 a 5 nos sinais acústicos das telhas. Os valores calculados para o coeficiente de atenuação foram obtidos com os pares de amplitudes adjacentes representados pelos pontos 2 e 3,3 e 4 , e 4 e 5 , cujos valores estão na Tabela 1 .

Os valores estimados para o coeficiente de atenuação da telha branca variaram entre - 0,018 dB/cm e - 0,020 $\mathrm{dB} / \mathrm{cm}$. Para a telha vermelha, esses valores são um pouco maiores, variando entre - 0,020 dB/cm e - 0,024 $\mathrm{dB} / \mathrm{cm}$. Esse resultado sugere que a onda acústica é mais atenuada na telha vermelha do que na telha branca.

\subsection{Análise da amplitude de impacto}

Para investigar os sinais acústicos de forma mais detalhada, a região de maior amplitude gerada no momento do impacto com a esfera (ponto 1) foi ampliada na faixa compreendida entre $7 \mathrm{~ms}$ e $11 \mathrm{~ms}$. Com a ampliação foi possível constatar que o pico de maior amplitude para a telha branca é de fato constituído por outros três picos sobrepostos, conforme ilustra a Figura 10. O valor médio de localização dos picos sobrepostos no eixo do tempo e seus respectivos desvios-padrão, em ms, são: P1 $=9,83 \pm 0,12, \mathrm{P} 2=10,14 \pm 0,71$ e $\mathrm{P} 3=10,57 \pm 0,12$. Os resultados mostram pouca variação na localização desses picos em função do número de medidas realizadas, como sugerem os baixos valores de desvio-padrão. Em todas as medidas realizadas nas telhas brancas, os picos P1 e P2 se apresentaram com valores próximos de amplitude, enquanto o pico P3 apresentou uma amplitude mais baixa.

A Figura 11 mostra o resultado da ampliação do ponto 1 no sinal acústico da telha vermelha. Nesse resultado 
Tabela 1: Estimativa dos coeficientes de atenuação $(\alpha)$.

\begin{tabular}{lccc}
\hline \multicolumn{4}{c}{ Telha branca $(\mathbf{x}=\mathbf{6 0} \mathbf{~ c m})$} \\
\hline $\mathbf{2}$ & $\mathbf{3}$ & $\mathbf{3} / \mathbf{2}$ & $\alpha \mathbf{( d B} / \mathbf{c m})$ \\
\hline$A_{o}=6,600$ & $A=5,846$ & $A / A_{o}=0,886$ & $-0,018$ \\
\hline $\mathbf{3}$ & $\mathbf{4}$ & $\mathbf{4} / \mathbf{3}$ & $\alpha(\mathbf{d B} / \mathbf{c m})$ \\
\hline$A_{o}=5,846$ & $A=5,084$ & $A / A_{o}=0,870$ & $-0,020$ \\
\hline $\mathbf{4}$ & $\mathbf{5}$ & $\mathbf{5} / \mathbf{4}$ & $\alpha(\mathbf{d B} / \mathbf{c m})$ \\
\hline$A_{o}=5,084$ & $A=4,460$ & $A / A_{o}=0,877$ & $-0,019$ \\
\hline \multicolumn{4}{c}{ Telha vermelha $(\mathbf{x}=\mathbf{6 0} \mathbf{~ c m})$} \\
\hline $\mathbf{2}$ & $\mathbf{3}$ & $\mathbf{3} / \mathbf{2}$ & $\alpha(\mathbf{d B} / \mathbf{c m})$ \\
\hline$A_{o}=6,246$ & $A=5,421$ & $A / A_{o}=0,868$ & $-0,020$ \\
\hline $\mathbf{3}$ & $\mathbf{4}$ & $\mathbf{4} / \mathbf{3}$ & $\alpha(\mathbf{d B} / \mathbf{c m})$ \\
\hline$A_{o}=5,421$ & $A=4,592$ & $A / A_{o}=0,847$ & $-0,024$ \\
\hline $\mathbf{4}$ & $\mathbf{5}$ & $\mathbf{5} / \mathbf{4}$ & $\alpha(\mathbf{d B} / \mathbf{c m})$ \\
\hline$A_{o}=4,592$ & $A=4,008$ & $A / A_{o}=0,872$ & $-0,020$ \\
\hline
\end{tabular}

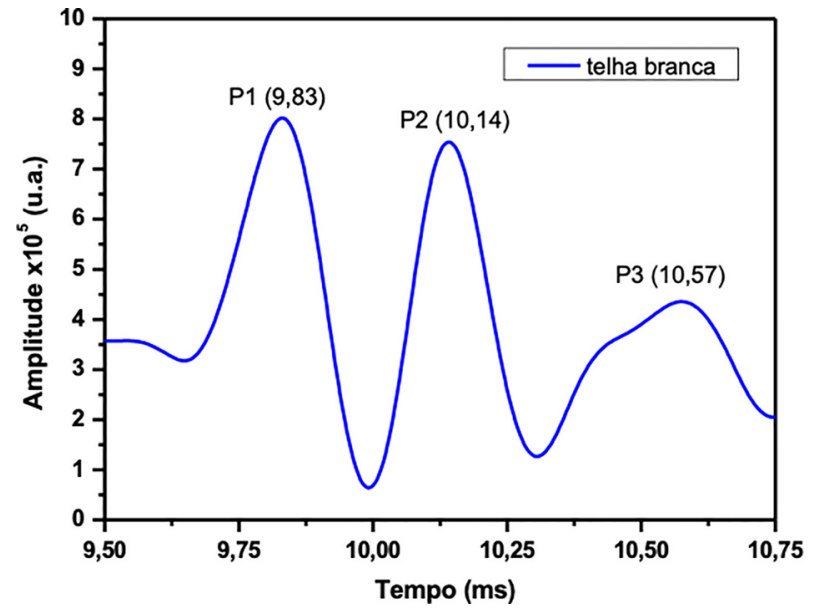

Figura 10: Ampliação da amplitude de impacto no sinal acústico da telha branca.

também é possível constatar que o pico é constituído por outros três picos sobrepostos. O valor médio de localização dos picos no eixo do tempo e seus respectivos desvios-padrão, em ms, são: $\mathrm{P} 1=7,22 \pm 0,11, \mathrm{P} 2=$ $7,49 \pm 0,12$ e P3 $=7,71 \pm 0,15$. Os valores de desvio padrão indicam pouca variação na localização desses picos em função do número de medidas nas telhas vermelhas. Comparando com os picos presentes na Figura 10, um comportamento diferente é observado para os picos P2 e P3, que apresentaram valores próximos de amplitude, mas inferiores ao valor da amplitude do pico P1.

A origem dos picos sobrepostos na amplitude de impacto é uma característica intrínseca do material investigado, combinada ao sistema experimental adotado. Se o experimento for realizado em um material diferente, como por exemplo, em aço ou uma madeira, possivelmente, o pico de amplitude no momento do impacto pode ser diferente, bem como o número de picos que o constitui. Por outro lado, se as telhas cerâmicas fossem investigadas usando um fone de ouvido, diferente daquele especificado no experimento, o sinal no momento do impacto também poderia ser diferente. Logo, para a reprodução do experimento e comparações entre resulta-

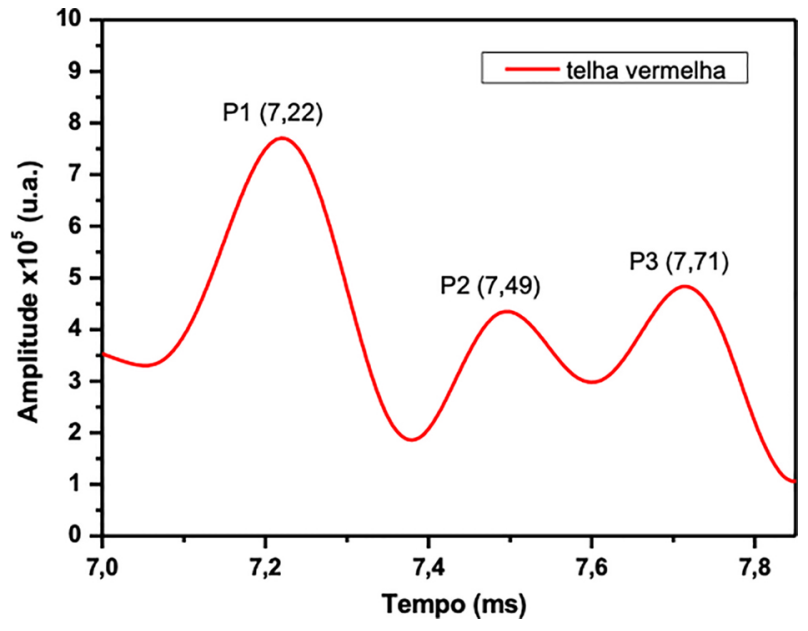

Figura 11: Ampliação da amplitude de impacto no sinal acústico da telha vermelha.

dos, todas as condições descritas na metodologia devem ser consideradas.

Com as ampliações realizadas nas regiões das amplitudes de impacto foi possível verificar uma sutil diferença entre os sinais acústicos das telhas branca e vermelha. Entretanto, os resultados encontrados com essa análise ainda não expressam com clareza as diferentes características de resistência à flexão e percentual de absorção relatadas pelos fornecedores das telhas investigadas.

\subsection{Análise dos intervalos de tempo}

As análises dos intervalos de tempo entre os picos de amplitudes adjacentes estão representadas nas Figuras 12 e 13 . Os pontos de 1 a 4 foram escolhidos para essa análise por representarem as maiores amplitudes decrescentes, estando os outros pontos mais próximos da região amortecida do sinal acústico. Os resultados mostram que na telha branca (Figura 12) o intervalo de tempo entre as amplitudes dos pontos 1 e 2 é de 4,309 ms. Entre os pontos 2 e 3 , e 3 e 4 , os valores estão em torno de 3,356 ms. 
Para o sinal acústico da telha vermelha (Figura 13) nota-se que o intervalo de tempo entre as amplitudes dos pontos 1 e 2 é de 5,941 ms. Esse valor é 1,632 ms maior do que àquele encontrado para a telha branca. Entre os pontos 2 e 3, e 3 e 4, os valores também foram um pouco maiores, estando em torno de 4,444 ms. Esses resultados estão de acordo com os resultados da Tabela 1 , onde foram estimados maiores valores de coeficiente de atenuação acústica para a telha vermelha.

\subsection{Análise dos sinais acústicos no domínio da frequência}

As funções temporais dos sinais acústicos decompostas no domínio da frequência estão apresentadas nas Figuras 14 e 15. Com a aplicação da Transformada Rápida de Fourier (FFT) realizada no programa Origin $7.0^{R}$ foi possível observar que o espectro de frequência da telha branca (Figura 14) é constituído por 8 picos característicos de amplitude, compreendidos na faixa de frequência

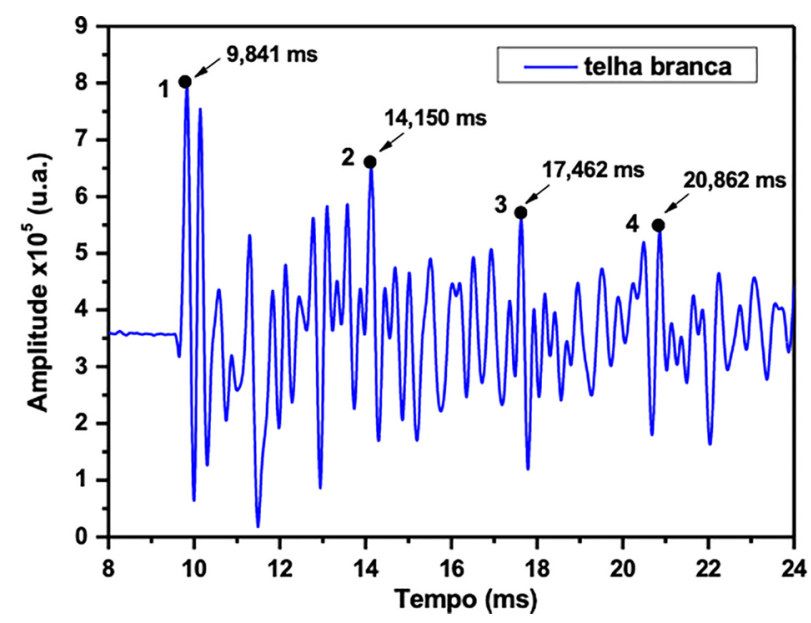

Figura 12: Intervalo de tempo entre as amplitudes no sinal da telha branca.

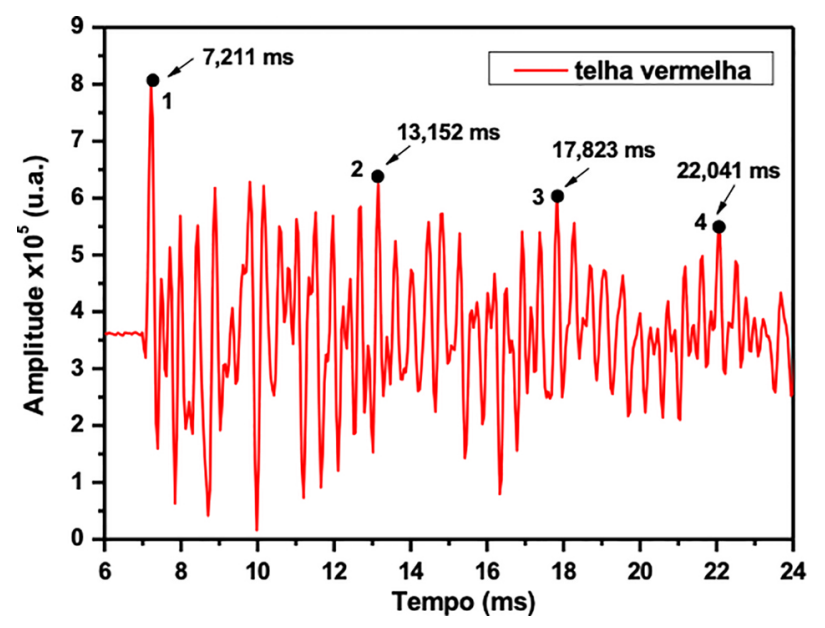

Figura 13: Intervalo de tempo entre as amplitudes no sinal da telha vermelha.

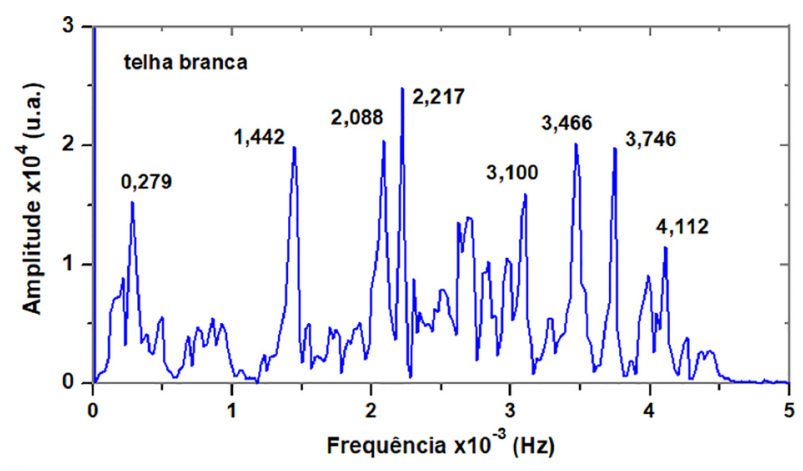

Figura 14: Espectro no domínio da frequência para a telha branca.

entre 0 e 0,005 Hz. Por outro lado, no espectro da telha vermelha (Figura 15) foram identificados apenas 4 picos característicos de amplitude para mesma faixa de frequência investigada. Nota-se ainda que, com exceção do pico a $0,279 \mathrm{~Hz}$ que encontra-se sobreposto, os picos presentes no espectro da telha branca não coincidem com nenhum pico mostrado no espectro da telha vermelha, conforme ilustra as linhas azuis na Figura 15.

Na Figura 14, os 8 picos de amplitudes denominados de picos característicos, foram ressaltados por estarem presentes em todas as medidas realizadas e por se apresentarem sempre com os maiores valores de amplitude. Os demais picos presentes no espectro nem sempre foram observados entre as medidas ou surgiram sobrepostos, ou ainda, com valores muito baixos amplitude. Essa análise também foi realizada no espectro da vermelha e por isso foram ressaltados apenas os 4 picos característicos na Figura 15.

Toda forma de onda, inclusive a onda acústica, é constituída por um somatório de ondas senoidais com diferentes frequências, amplitudes e fases [8]. O impacto produzido pela esfera de aço sobre a superfície das telhas gera ondas acústicas com movimentos oscilatórios que excitam várias frequências, sendo esses valores influenciados pela superfície de propagação da onda acústica e pelas ca-

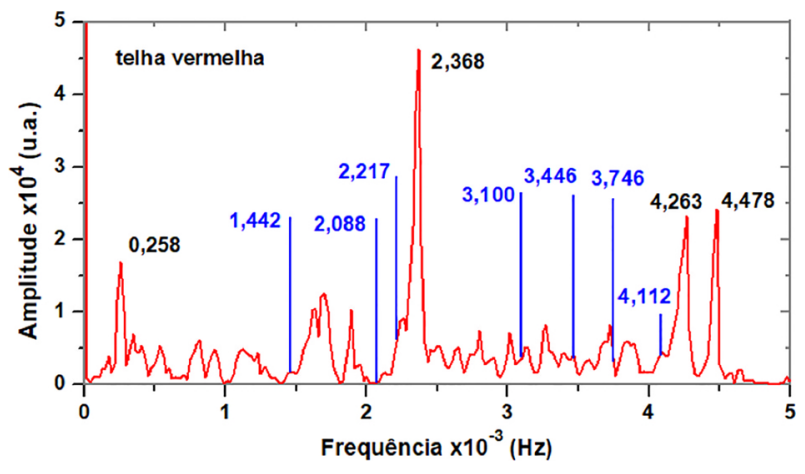

Figura 15: Espectro no domínio da frequência para a telha vermelha com a localização em azul dos picos característicos da telha branca. 
racterísticas físicas e mecânicas das telhas. Nesse caso, os diferentes espectros de frequência apresentados nas Figuras 14 e 15 podem estar relacionados, sobretudo, com a propagação das ondas acústicas por superfícies com diferentes características morfológicas.

As Figuras 16 e 17 apresentam as imagens capturadas na superfície das telhas com microscopia óptica. Analisando as imagens obtidas em diferentes regiões da telha branca, nota-se uma superfície mais homogênea, constituída de pequenos poros e com baixa presença de microtrincas, conforme mostra as Figuras 16(a) e (b). Em geral, no processo de fabricação das telhas brancas, elas recebem uma camada protetora de resina, que varia entre 2 e 3 milímetros de espessura. Esse procedimento diminuiu de forma significativa a porosidade e a presença de microtrincas na superfície, contribuindo para um menor percentual de absorção de água. Os poros preenchidos por resina se destacam em regiões mais claras, que são decorrentes do reflexo da luz emitida pelo microscópio.

De acordo com alguns estudos da ciência e engenharia de materiais, uma superfície mais homogênea e livre de pequenas falhas também aumenta a tenacidade à fratura, que consiste na capacidade do material resistir à propagação de trincas $[2,10]$.

Para a superfície da telha vermelha percebe-se uma morfologia diferente. Na Figura 17(a) é possível perceber a presença de vários poros e microtrincas, que constitui uma superfície com menor homogeneidade de defeitos, quando comparada com a superfície da telha branca. Realizando uma varredura na superfície da telha vermelha foi possível observar falhas com dimensões superiores a 0,5 mm, conforme ilustra a Figura 17 (b). Essas características eram esperadas, tendo em vista que as telhas vermelhas não receberam nenhum tratamento especial na superfície.
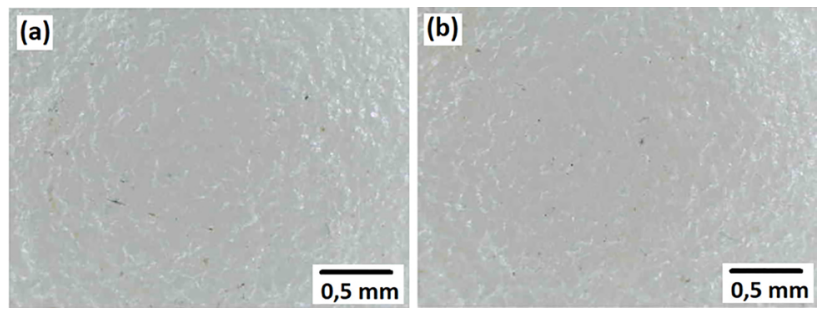

Figura 16: Morfologia da superfície na telha branca (aumento: 10x).
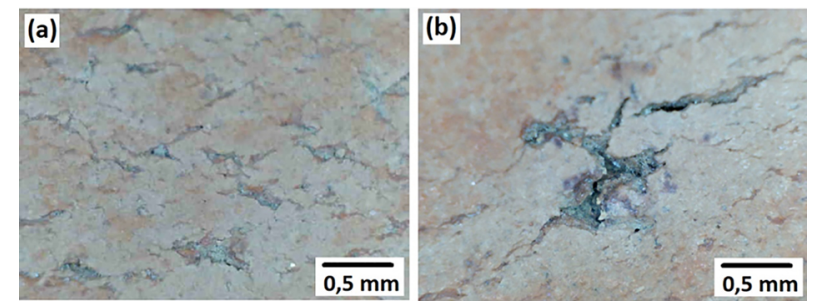

Figura 17: Morfologia da superfície na telha vermelha (aumento: $10 x)$.
Comparando as superfícies das telhas é possível compreender por que a telha branca possui um menor percentual de absorção de água e uma maior resistência à flexão. Com uma superfície mais homogênea e com menor porosidade, as telhas brancas resinadas alcançam um percentual de absorção de água em torno de $4 \%$ e uma resistência à flexão de $250 \mathrm{kgf}$, conforme relatado pelo fabricante. O percentual de absorção de água para a telha vermelha é bem maior, estando em torno de $13 \%$, enquanto a resistência à flexão é menor, sendo de 180 kgf. A característica da superfície da telha vermelha também explica a tendência dos maiores valores estimados para o coeficiente de atenuação apresentados na Tabela 1.

Alguns autores relatam que as telhas brancas são compostas por argilas que apresentam alto percentual de sílica e óxido de alumínio, além do mineral caulinita. Já as telhas vermelhas, além da sílica, apresentam uma mistura de outros minerais como quartzo, óxido de alumínio e óxido de ferro [11]. Portanto, admitindo uma situação hipotética, onde sejam investigadas telhas brancas e vermelhas idênticas, ambas resinadas e com mesmas características superficiais, a composição química poderia ser associada aos espectros obtidos no domínio da frequência, nos casos onde eles se apresentarem diferentes. Entretanto, as associações com os espectros seriam feitas em relação à composição química geral, sendo descartadas as associações feitas à presença de um elemento químico específico. Para comprovar essa hipótese, ainda é necessário realizar experimentos e estudos mais aprofundados.

\section{Conclusão}

Os resultados desta pesquisa permitiram concluir que os sinais acústicos encontrados para as telhas brancas e vermelhas apresentaram decaimentos exponenciais semelhantes, com uma pequena diferença na constituição dos picos de maior amplitude obtidos no momento do impacto. Entretanto, os valores calculados para o coeficiente de atenuação sugerem que a propagação da onda acústica é mais atenuada na telha vermelha.

Os valores de intervalo de tempo entre as amplitudes de reflexão também sugerem um leve atraso na onda acústica propagada nas telhas vermelhas, concordando com os maiores valores dos coeficientes de atenuação.

Embora tenha sido possível perceber algumas diferenças entre os sinais acústicos em função do tempo, eles não expressaram claramente uma relação com as características físicas e mecânicas relatadas pelos fabricantes. Por outro lado, os sinais acústicos investigados no domínio da frequência, aliados às imagens obtidas nas superfícies das telhas, reforçam as relações existentes entre a morfologia da superfície, o percentual de absorção e a resistência à flexão das telhas.

A metodologia utilizada foi capaz de identificar, por meio da análise de ondas acústicas, algumas diferenças existentes entre dois grupos de amostras de telhas ame- 
ricanas. Logo, os resultados indicam que a metodologia proposta pode ser aplicada para caracterizar outros tipos de telhas cerâmicas. Contudo, devem ser realizados mais ensaios com diferentes tipos de telhas cerâmicas para que essa hipótese seja comprovada.

O experimento realizado se apresenta como uma alternativa rápida para a investigação das telhas cerâmicas nas aulas de Materiais de Construção. Por ser um método não destrutivo, a caracterização das telhas pode ser feita sem produzir resíduos sólidos, que são provenientes dos ensaios destrutivos tradicionais. Portanto, o experimento proposto com ondas acústicas pode contribuir de forma bastante didática com as aulas de laboratório de Materiais de Construção, ministradas nos cursos de Engenharia Civil de diversas Instituições de Ensino Superior (IES).

\section{Referências}

[1] Associação Brasileira de Normas Técnicas - ABNT. NBR 15310: Componentes cerâmicos - Telhas - Terminologia, Requisitos e Métodos de ensaio (ABNT, Rio de Janeiro, 2005).

[2] A. Garcia, J.A. Spim e C.A. Santos, Ensaios dos Materiais (LTC, Rio de Janeiro, 2012), $2^{\mathrm{a}}$ ed.

[3] S.L. Piubelli, H.A. Errobidart, S.T. Gobara e N.C.G. Errobidart, Rev. Bras. Ens. Fís. 32, 1501 (2010).

[4] J.W. Jewet Jr e R.A. Serway, Física para cientistas e engenheiros - Oscilações, ondas e termodinâmica (Cengage, São Paulo, 2017), v. 2, 9a ed.

[5] R. Palani e J. Selvarasi, Int J Cur Res Rev 9, 71 (2017).

[6] A.P. dos Santos Neto e P. Ferreira, Teoria e Prática na Engenharia Civil 6, 59 (2005).

[7] J. Krautkramer e H. Krautkramer, UItrasonic Testing of Materials (Springer-Verlag, Berlin, 1990), $4^{\mathrm{a}}$ ed.

[8] J.L. deLyra, Métodos Matemáticos para Física e Engenharia: Transformadas de Fourier (Livraria da Física, São Paulo, 2014), v. 2.

[9] M. Varanis, A.L. Silva, P.H.A. Brunetto e R.F. Gregolin, Rev. Bras. Ens. Fís. 38, 1 (2016).

[10] W.D. Callister Jr e D.G. Rethwisch, Ciência e Engenharia de materiais: Uma introdução (LTC, Rio de Janeiro, 2016), $9^{\text {a }}$ ed.

[11] A.B. Luz e F.A.F. Lins, Rochas \& minerais industriais: usos e especificações, (CETEM-MCT, Rio de Janeiro, 2008). 